\title{
Delusional Parasitosis with Associated Thyroid Abnormality
}

\author{
Anagha Kumar, Shwethashree M, Anwith H.S
}

\begin{abstract}
Delusion of parasitosis is a rare, monosymptomatic psychosis involving a delusion of being infested with parasites seen commonly in females. It is classified as a 'delusional disorder' according to the 10th revision of the International Classification of Diseases and as a 'delusional disorder - somatic type' according to the Diagnostic and Statistical Manual, Fourth Edition. We present this rare case of delusional parasitosis in an elderly female with her symptoms paralleling her thyroid profile. Case presentation: Our patient was a 68-year-old, South Indian woman with primary school education who had been living alone for the past twenty years. She presented to our out patient department complaining of multiple worms on her body. However, on examination, no worms or skin disease was evident. She was also diagnosed with hyperthyroidism; with exacerbation of delusions with increased thyroid hormones ad vice versa. She was treated with antithyroid medication and with pimozide $2 \mathrm{mg} /$ day for 10 months and followed-up without any antipsychotic treatment for an additional five months. At her last examination, she was euthyroid, not receiving antipsychotics and was not having any delusions. Conclusion: Rarely, few endocrine conditions like hyperthyroidism can cause secondary delusional parasitosis. This case demonstrated a rare occurrence of correlation of symptoms with her thyroid profile.
\end{abstract}

Keywords: Delusion, Parasitosis, Ekbom's syndrome, thyroid

\section{Introduction}

Delusional parasitosis (DP) is a monosymptomatic psychosis involving a delusion of being infested with parasites [1]. Usually seen in elderly females living alone but their occurrence in men is not rare. It is more commonly reported in the Western society. Patients with DP believe that insects, worms or other small pests live in their bodies and feed on them [2]. It is accompanied by tactile and probably visual hallucinations of having parasites on the body. Primary DP is a psychiatric disorder whereas secondary DP is currently thought of as a symptom that is secondary to another psychopathology or a medical illness $[4,5]$. Secondary DP has been associated with diseases and malignancies of the hematopoietic, pulmonary, cardiac, renal, gastrointestinal and endocrine systems, infections of the central nervous system, and nutritional deficiencies including vitamin $\mathrm{B} 12$, folate and pellagra $[1-5,12,13]$. However, the causal role of any of these conditions has not been adequately proven.

Here, we report the treatment of a patient with Delusional parasitosis associated with hyperthyroidism. This case was deemed worthy of presentation due to its rarity in South Indian population and its association with hyperthyroidism.

\section{Case Presentation}

Our patient was a 69 -year-old South Indian widow living alone for the past 20 years. A non-smoker, non-alcoholic with primary school education, she presented to our outpatient department complaining ofworms moving over her body. The complaint had been present for the past 3 months . A thorough physical examination revealed excoriations on the back, abdomen and thighs. The patient had not made any attempt to collect the parasite or any debris. A treatment trail for scabies with Permethrine application was given to which the patient did not respond. Permethrine application was advised 1 week later to which the patient did bot feel better. She presented with the same complaints again and again and we decided to evaluate her and take a psychiatric consultation. Her routine investigations of complete blood count,liver function tests and renal funtion tests were normal.

Thyroid hormone profile, USG and FNAC showed features of Grave's disease.

Propylthiouracil $300 \mathrm{mg} /$ day and propranolol $30 \mathrm{mg} /$ day were started and the doses were maintained at $100 \mathrm{mg} /$ day and $40 \mathrm{mg} /$ day, respectively, after the first week. She was also put on Pimozide $2 \mathrm{mg} /$ day for delusions and propylthiouracil $100 \mathrm{mg} /$ day . The patient presented 20 days late to our OPD with complaints of worms on the body. On, provoking, she revealed she had stopped her thyroid medications. She was referred to the endocrinologist. Her routine laboratory workup of complete blood count, renal and liver functions was normal. Her VDRL was non reactive and there was no evidence of drug abuse. Table shows her thyroid status and symptom profile. Thyroid medication was started again and patient was advised to continue pimozide. After 4 months her thyroid hormone levels increased again due to an irregular use of medication and she also started feeling worms on her body.

\begin{tabular}{|c|c|c|c|c|}
\hline Date & T3 in ng/dl & Free T4 in ng/dl & TSH mlU/l & Delusions \\
\hline Baseline & 6.58 & 2.88 & 0.01 & present \\
\hline 2 months & 3.46 & 1.42 & 0.3 & nil \\
\hline 4 months & 4.08 & 2.66 & 0.02 & present \\
\hline 6 months & 2.32 & 1.96 & 0.03 & nil \\
\hline 8 months & 1.62 & 1.03 & 1.22 & nil \\
\hline 10 months & 0.88 & 0.99 & 1.32 & nil \\
\hline
\end{tabular}

Table 1 shows her thyroid profile during her follow up with her symptoms.

Her complaints disappeared when her thyroid condition was adequately controlled. After 10 months of followup the Pimozide was stopped and she was followed up without antipsychotic treatment for an additional 5 months. Currently,she is euthyroid and has not have any delusions.

\section{Volume 5 Issue 1, January 2016




\section{International Journal of Science and Research (IJSR) \\ ISSN (Online): 2319-7064}

Index Copernicus Value (2013): 6.14 | Impact Factor (2014): 5.611

Discussion We have reported a case of delusional parasitosis also know as Ekbom's syndrome thought to be due to hyperthyroidism and reported its treatment and followup. Many individuals with Delusional parasitosis are normally functioning while a few are severely effected. Patients usually present with a history of few months of feeling and even seeing worms on their body. These features were also present in our patient. Pimozide was used to treat our patient because. Several case reports have indicated the beneficial effects of atypical antipsychotics in primary DP, such as risperidone, quetiapine, olanzapine and amisulpride [610].The pathogenesis of DP is currently unknown however elevation of extracellular dopamine within the striatum; social isolation; or stress have be shown to play a role[7]. Social isolation, and hyperthyroidism may have played a role in our patient.

\section{Conclusion}

Our case showed a relationship between thyroid status and patients symptoms. She was managed successfully with antithyroid medications and Pimozide. This was a rare case of delusional parasitosis probably secondary to hyperthyroidism. More studies are needed to prove the relationship between dopaminergic neurotransmission in the brain and level of thyroid hormones.

\section{References}

[1] Driscoll MS, Rothe MJ, Grant-Kels JM, Hale MS: Delusional parasitosis: a dermatologic, psychiatric and pharmacologic approach. J Am Acad Dermatol 1993, 29:1023-1033.

[2] Ford EB, Calfee DP, Pearson RD: Delusions of intestinal parasitosis. South Med J 2001, 94:545-547.

[3] Ait-Ameur A, Bern P, Firoloni MP, Menecier P: [Delusional parasitosis or Ekbom's syndrome]. Rev Med Interne 2000, 21:182-186.

[4] Lyell A: The Michelson lecture: delusions of parasitosis. Br J Dermatol 1983, 108:485-499.

[5] Barsky AJ, Borus JF: Functional somatic syndromes. Ann Intern Med 1999, 130:910-921.

[6] Huber M, Kirchler E, Karner M, Pycha R: Delusional parasitosis and the dopamine transporter. A new insight of etiology Med Hypotheses 2007, 68:1351-1358.

[7] Lepping P, Russel I, Freudenmann RW: Antipsychotic treatment of primary delusional parasitosis: systematic review. Br J Psychiatry 2007, 191:198-205.

[8] Gallucci G, Beard G: Risperidone and the treatment of delusions of parasitosis in an elderly patient. Psychosomatics 1995, 36:578-580.

[9] Le K, Gonski PN: Delusional parasitosis mimicking cutaneous infestation in elderly patients. Med J Aust 2003, 179:209-210.

[10]Lepping P, Gil-Candon R, Freudenmann RW: Delusional parasitosis treated with amisulpride. Prog Neurol Psychiatry 2005, 9:12-16.

[11]Catic AG: Identification and management of inhospital drug- induced delirium in older patients. Drugs Aging 2011, 28(9):737-748.

[12] Ozten et al : Delusional parasitosis with hyperthyroidism in an elderly woman.Journal of medical case reports;2013,7(1):1
[13] Y. Furuhashi and M. Ishikawa, "Acute Normalization of Thyroxine Induced Hallucinations and Delusions, International Journal of Clinical Medicine, Vol. 3 No. 5, 2012, pp. 341-343 